ISSN (Print): 2709-9636 | ISSN (Online): 2709-9644

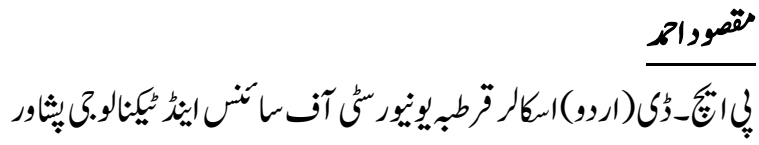

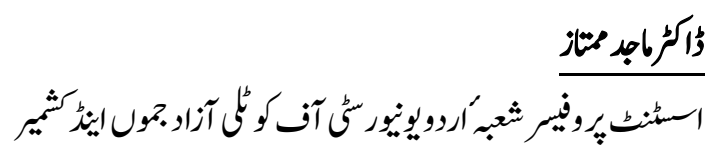

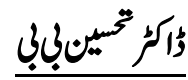

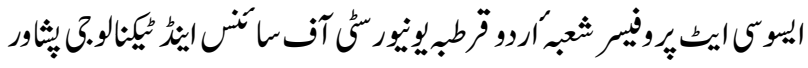

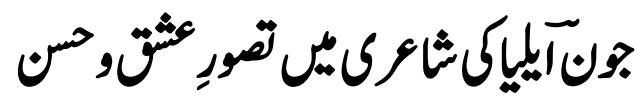

\title{
Maqsood Ahmad
}

Ph.d Research Scholar (Urdu), Qurtuba University Peshawar

Dr.Majid Mumtaz

Assistant Professor (Urdu) University of Kotli Azad jamu and Kashmir

\section{Dr.Tehseen Bibi}

Associate Professor (Urdu), Qurtuba University Peshawar

\section{The concept of Love and Beauty in Joun Elia's Poetry}

Joun Elia is one of the well- known names of modern Urdu poetry. He introduces the modern trends of Urdu poem and ode in poetry .He expressed his thoughts on different topics and gave a new touch and express to his thoughts. His poetry describes the concept of "love and beauty" with new trends. This article is going to describe and discuss. The different aspects of Joun Elia poetry with special reference to love and beauty.

Keywords: Thougts, History, Philosphy, Nostalgia, Fanciful Paradise, Poetic Features, Soft Tempers, Sensitiveness, Epoch Issues.

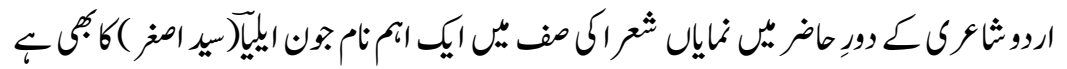

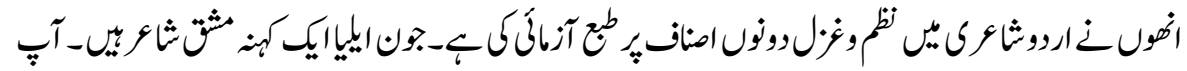

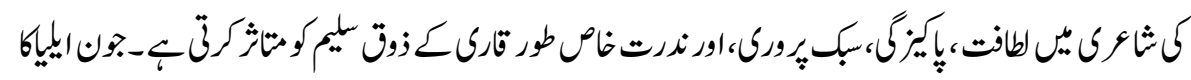

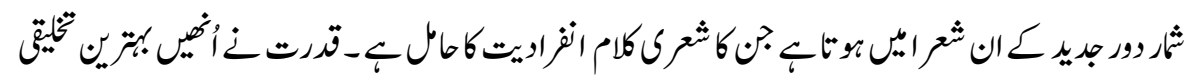


ISSN (Print): 2709-9636 | ISSN (Online): 2709-9644

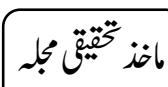

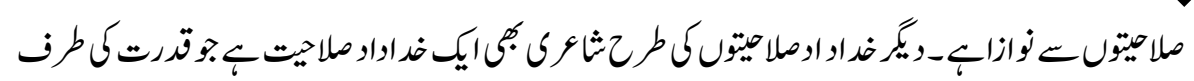

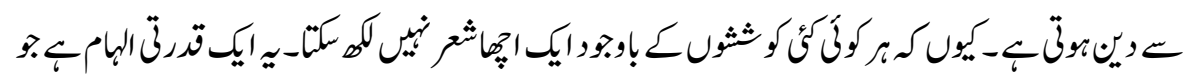

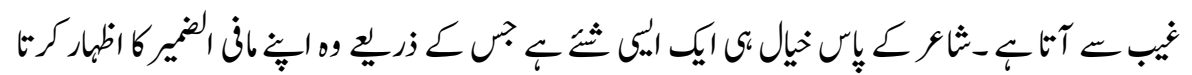

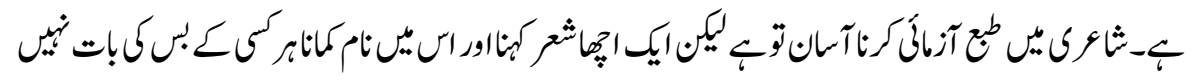

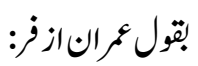

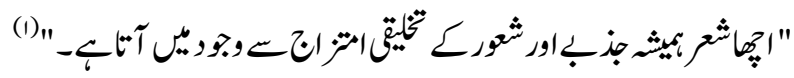

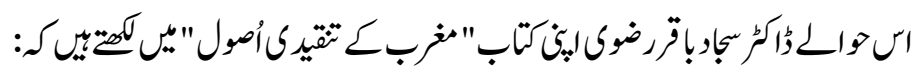

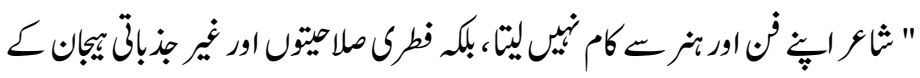

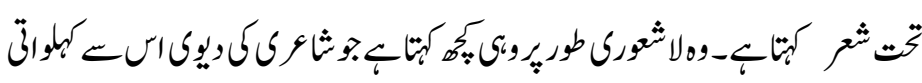

()$^{\prime \prime}-4$

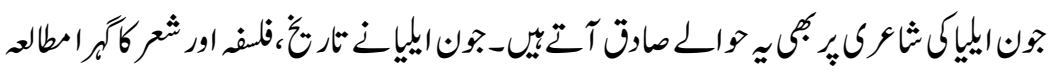

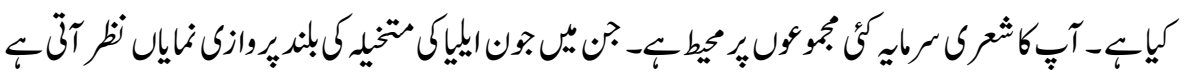

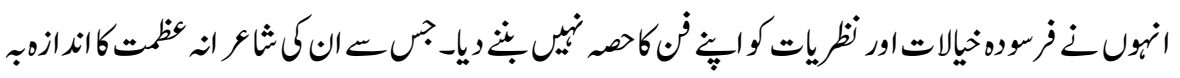

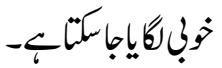

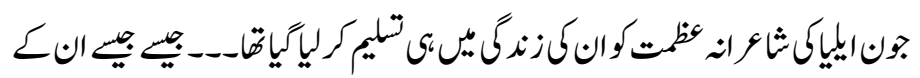

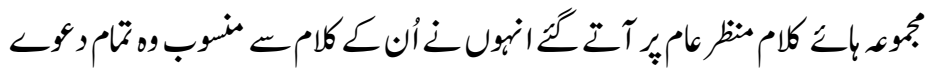

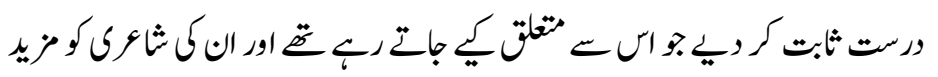

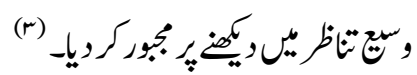

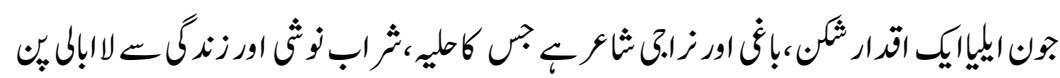

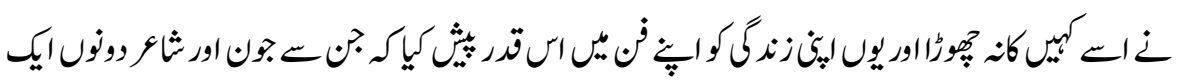

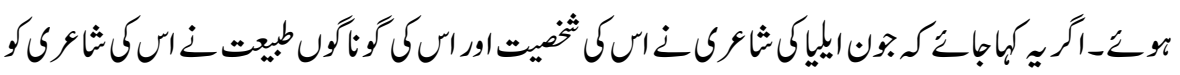

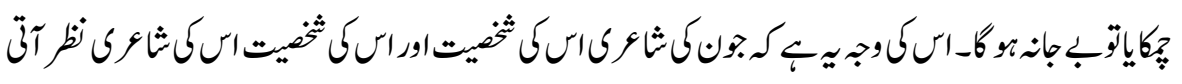

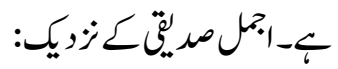

rrr 
ISSN (Print): 2709-9636 | ISSN (Online): 2709-9644

Volume 2, 2021(Issue III, July to September)

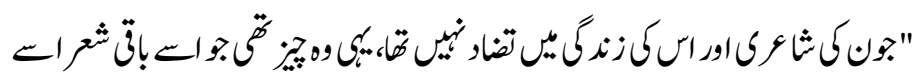

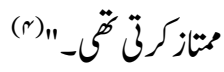

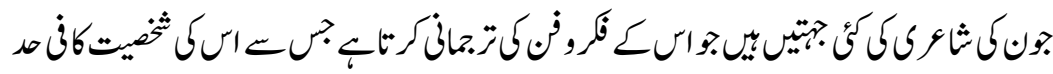

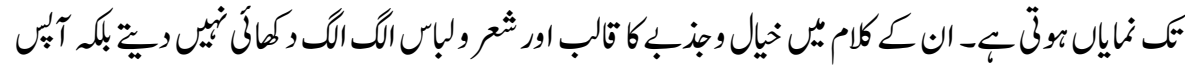

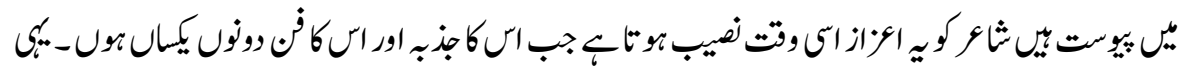

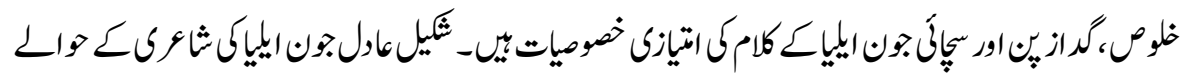

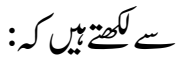

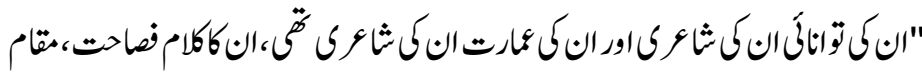

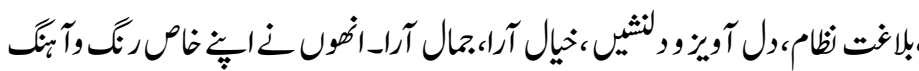

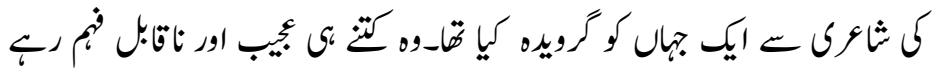

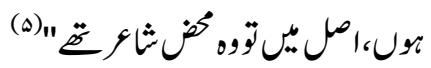

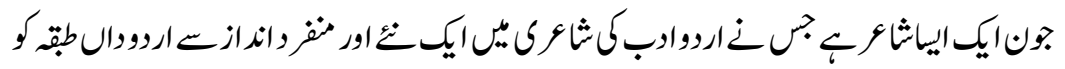

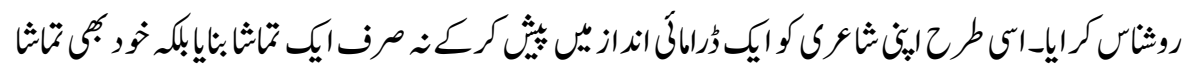

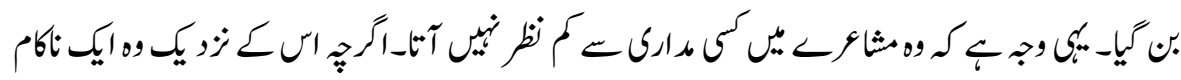

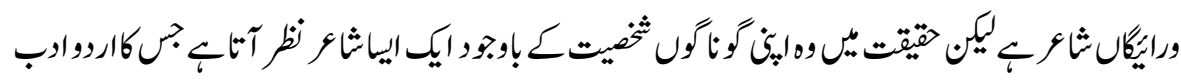

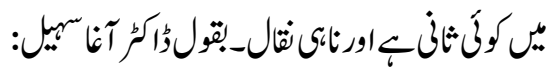

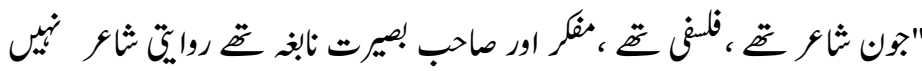
(4)" $-\ddot{\vec{E}}$

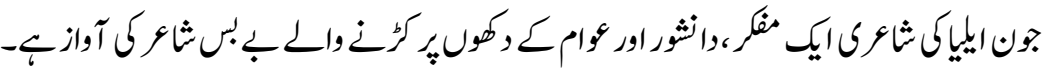

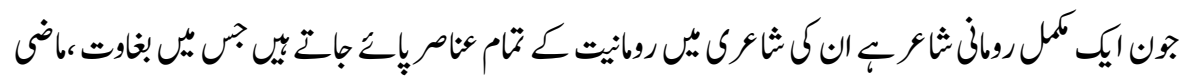

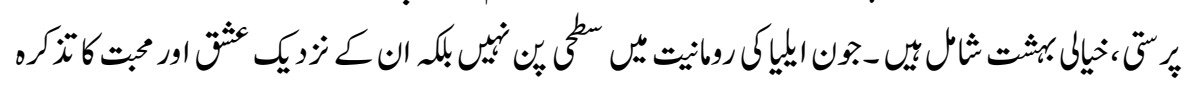

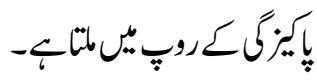




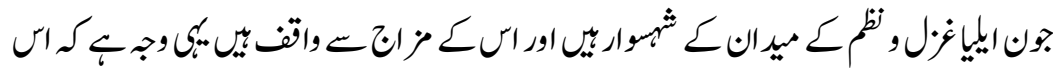

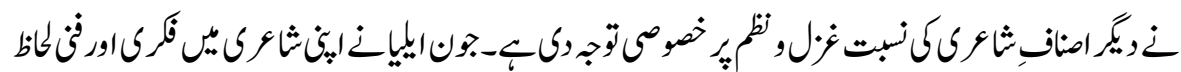

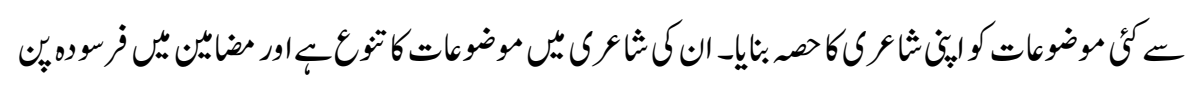

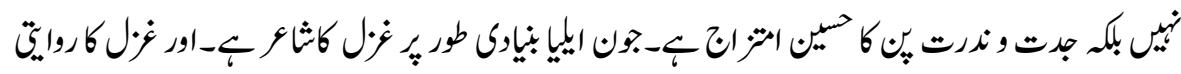

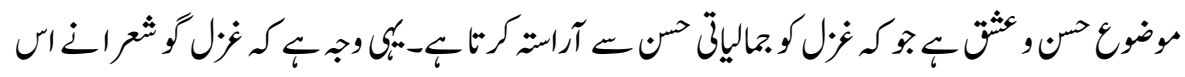

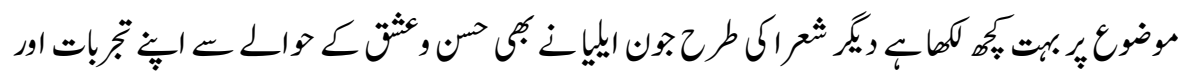

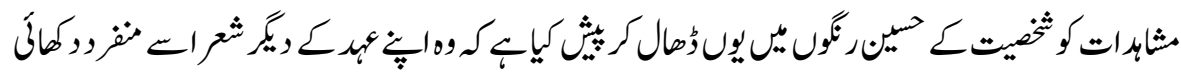
ويتاك-بقول الوبكر:

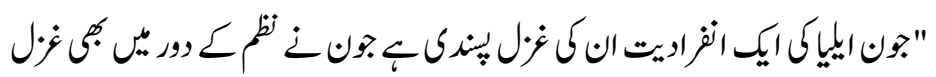

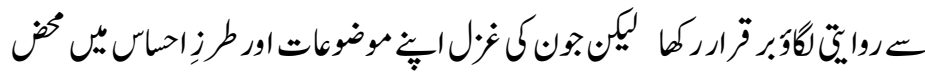

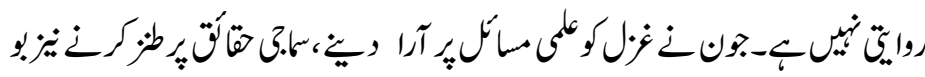

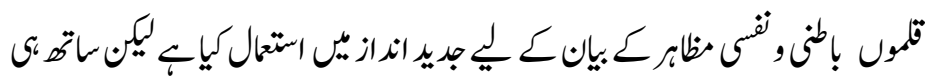

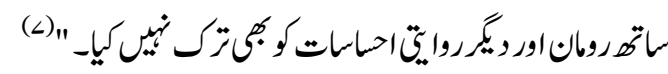

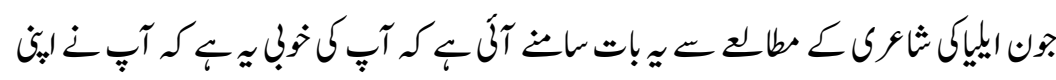

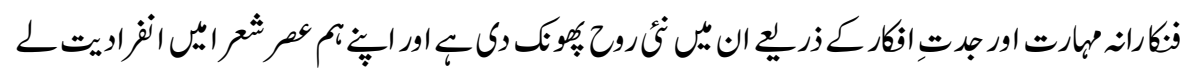

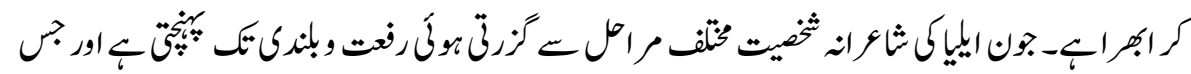

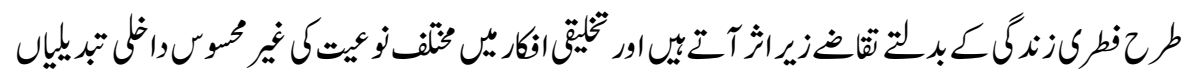

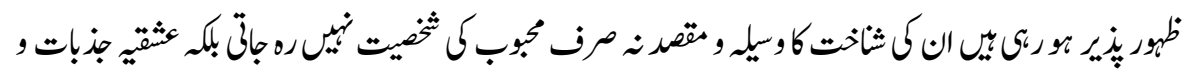

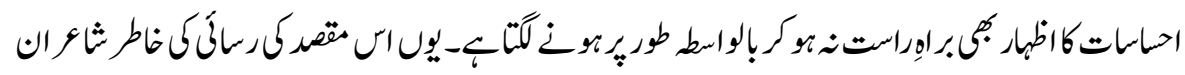

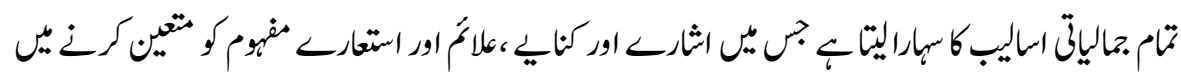
تضوص كروار اواكرت تبيك-

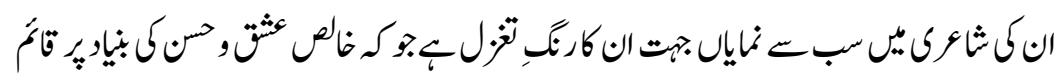

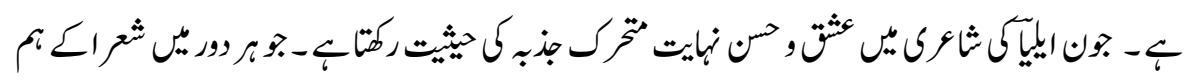




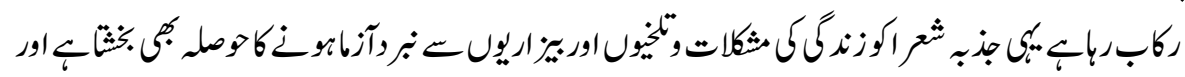

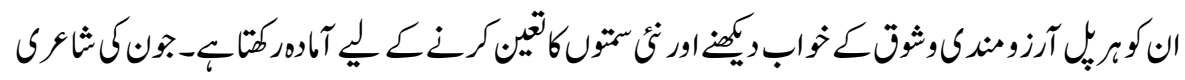

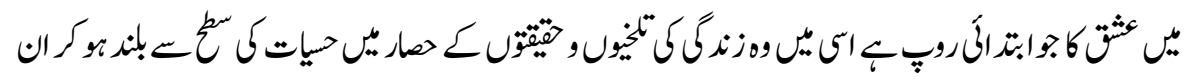

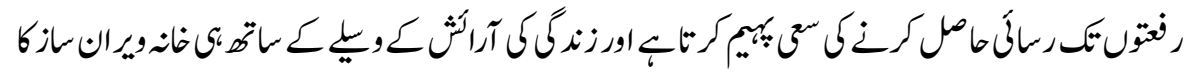

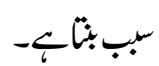

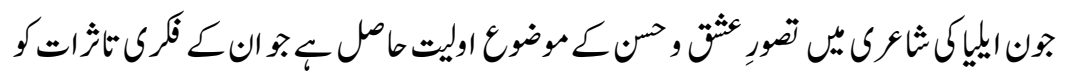

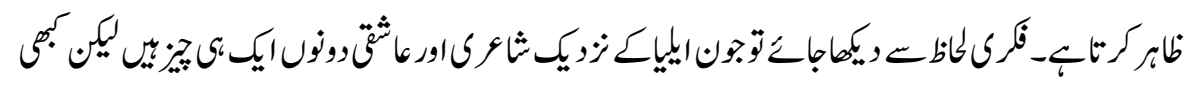

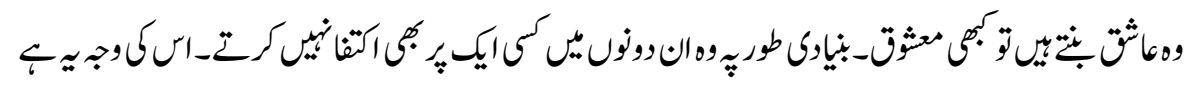

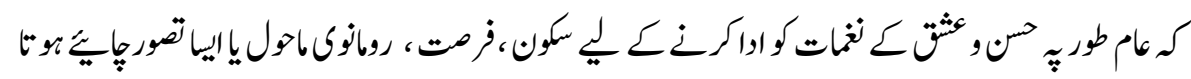

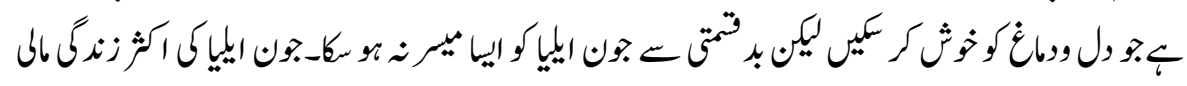

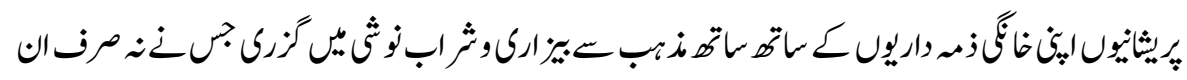

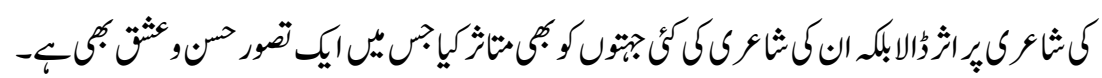

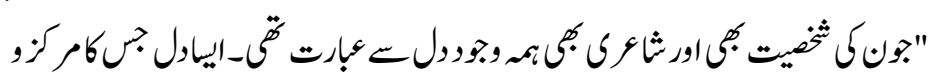

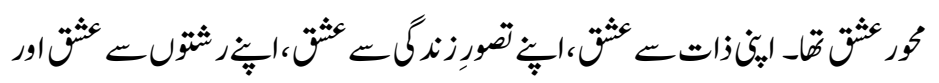

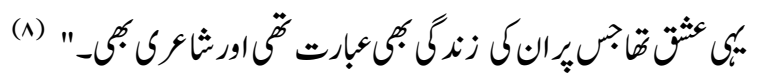

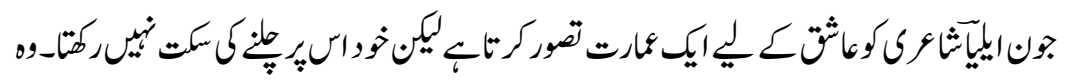

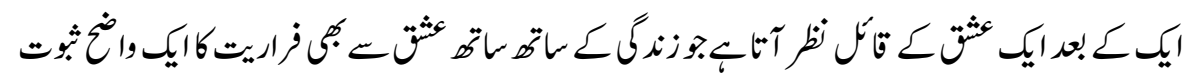

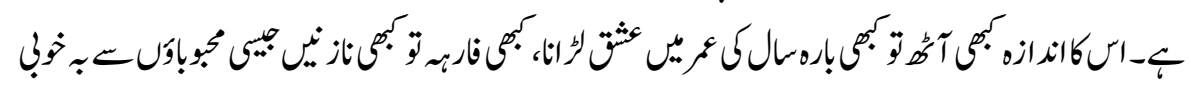

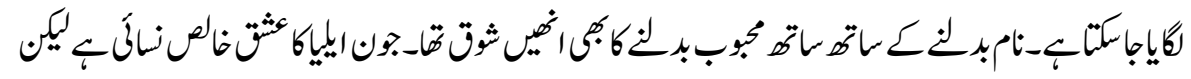

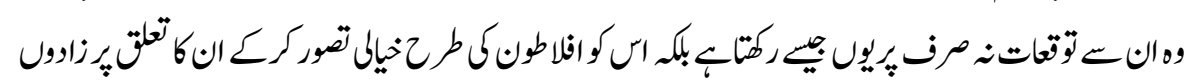

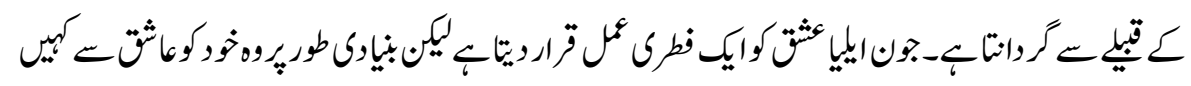

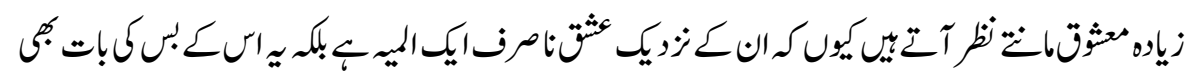

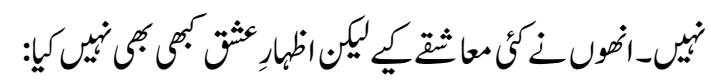




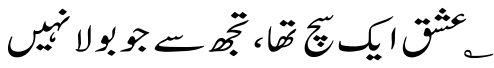

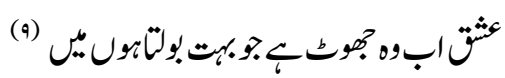

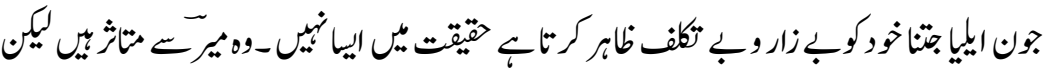

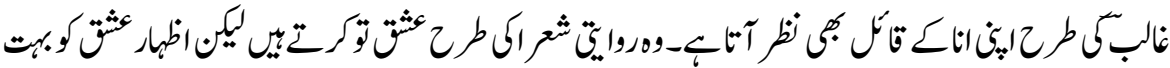

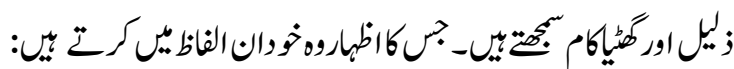

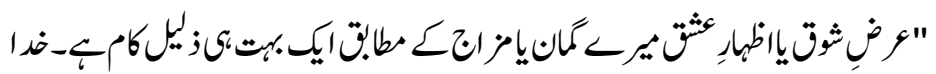

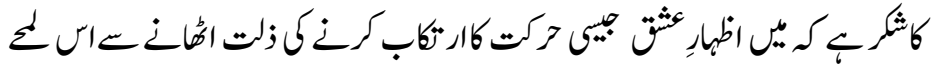

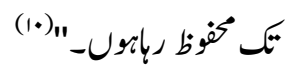

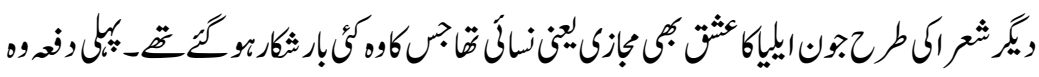

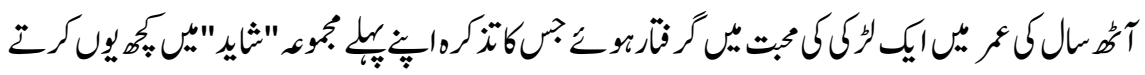

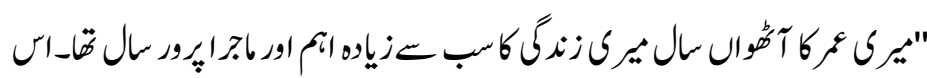

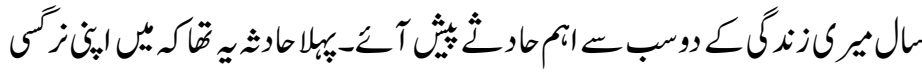

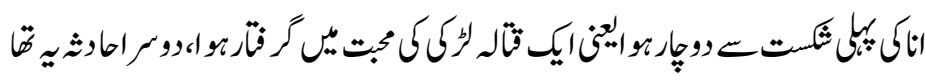

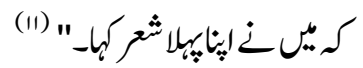

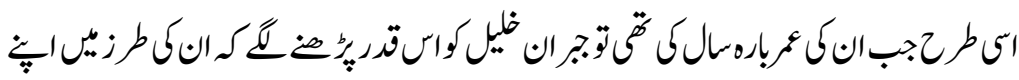

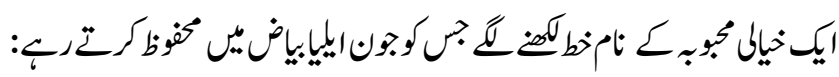

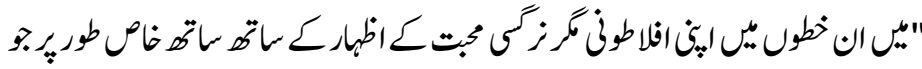

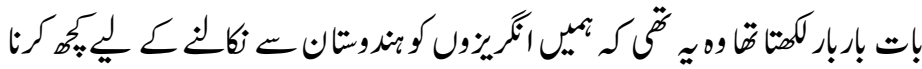

$$
\text { (ir) }
$$

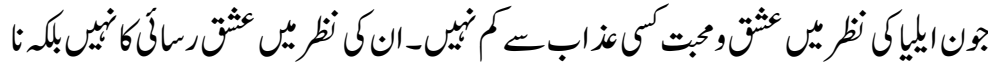

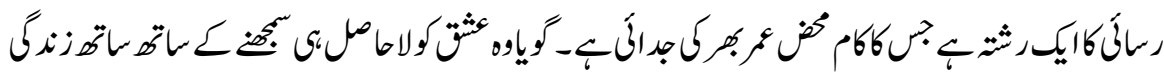

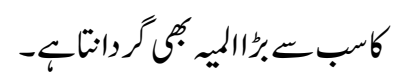




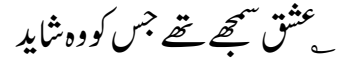

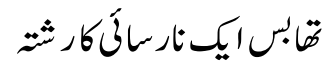

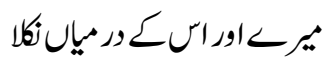

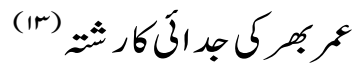

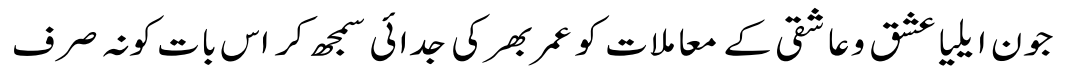

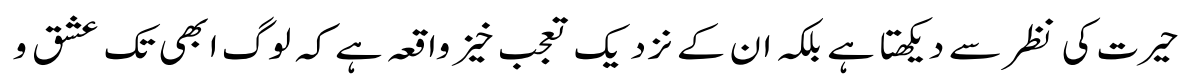

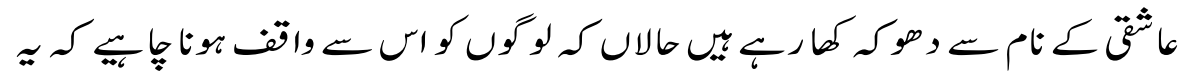

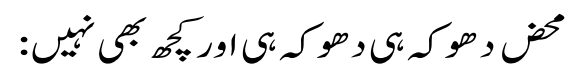

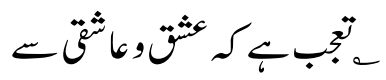

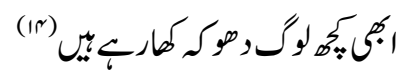

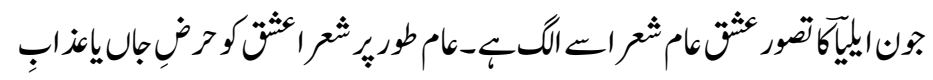

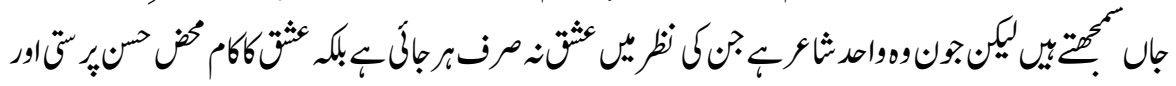

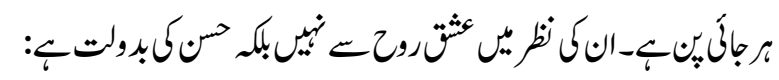
ه س

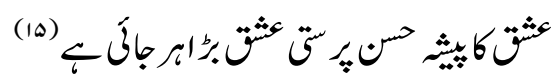

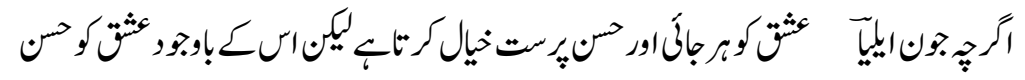

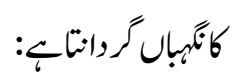

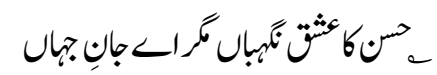

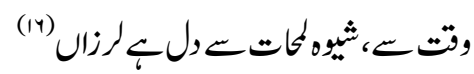

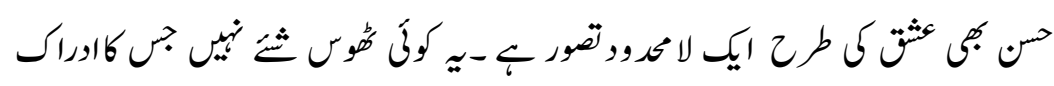

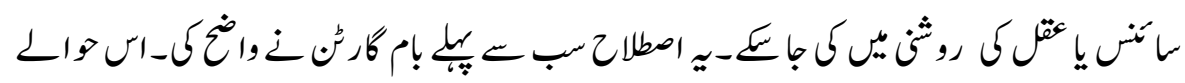

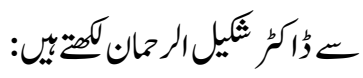




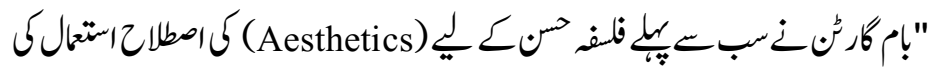

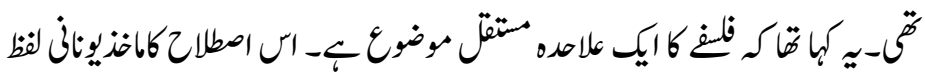
(Aestitiko)

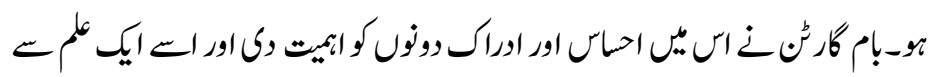

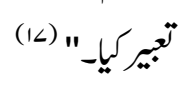

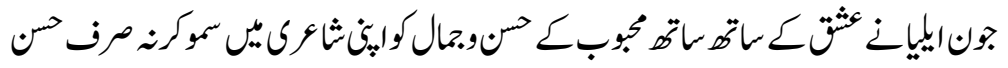

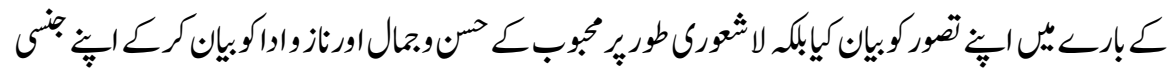

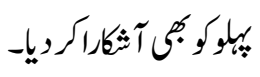

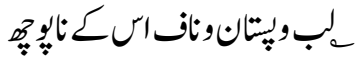

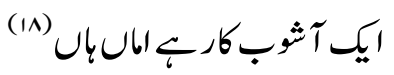

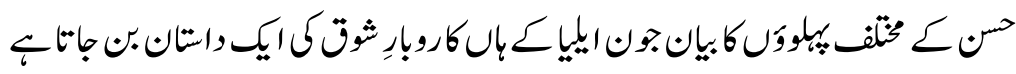

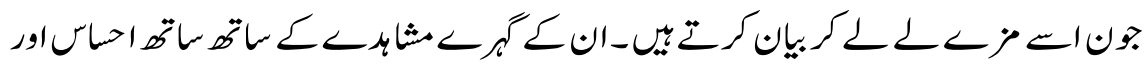

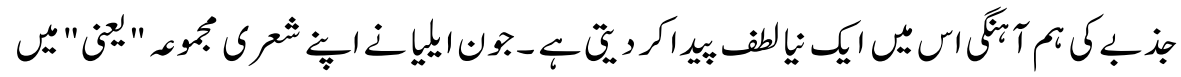

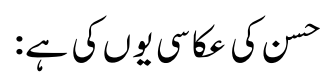

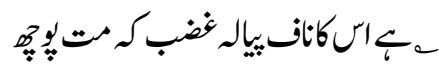

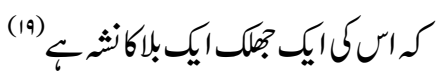

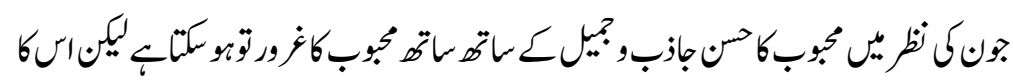

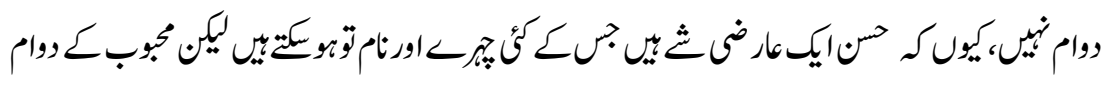

$$
\begin{aligned}
& \text { اورجيت ع لِير ليل نيّن: }
\end{aligned}
$$

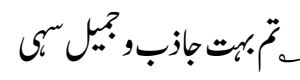

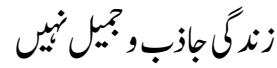

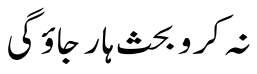

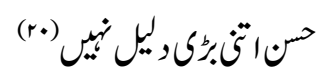




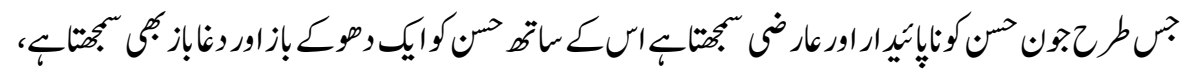

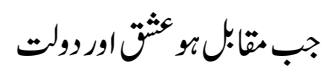

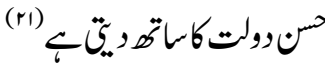

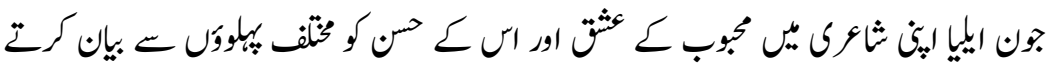

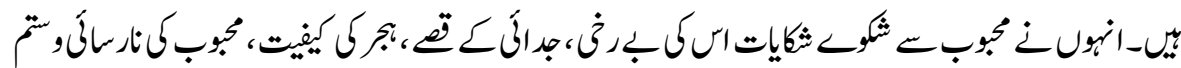

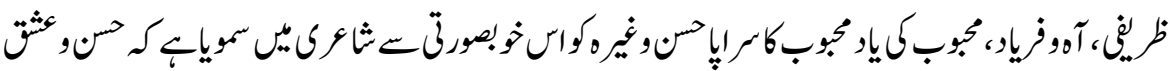

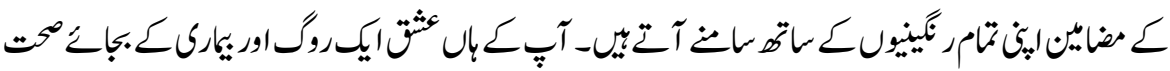

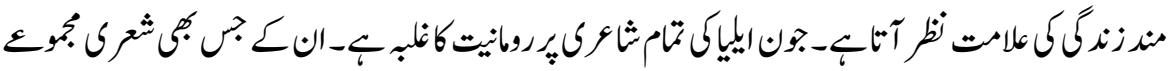

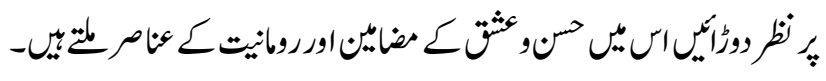

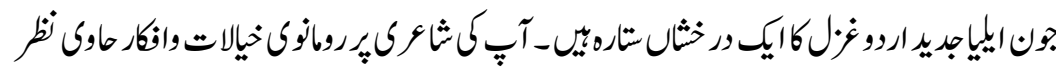

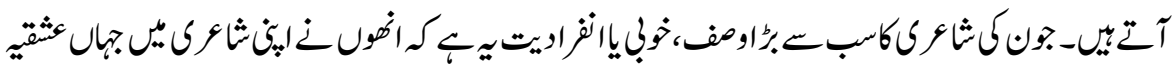

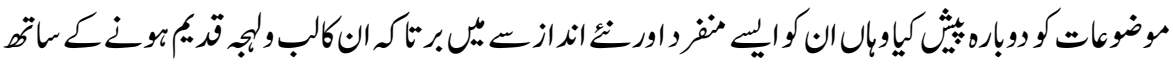

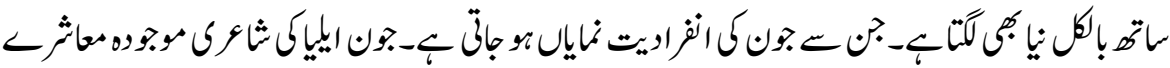

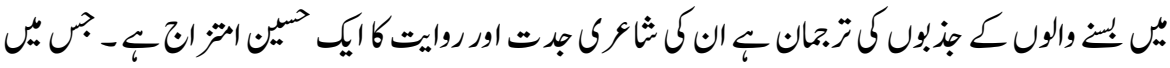

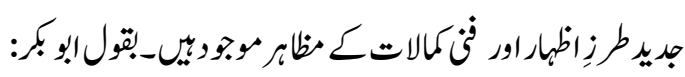

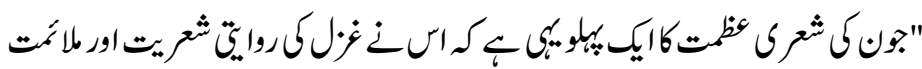

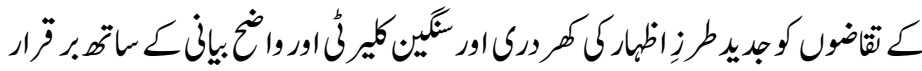

$$
\text { (rr) } "-46
$$

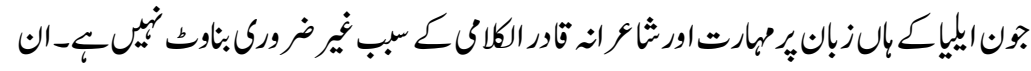

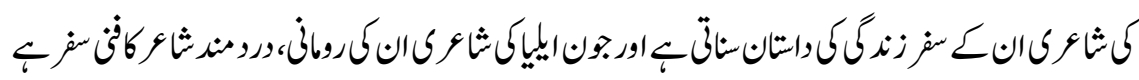

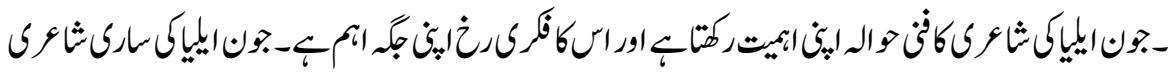

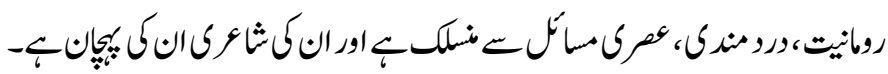




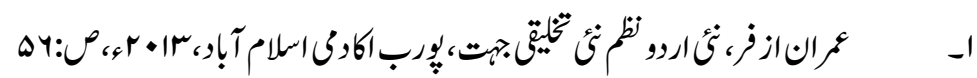

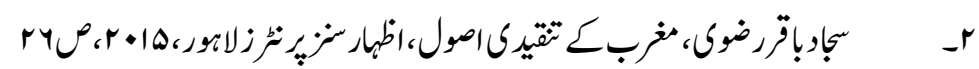

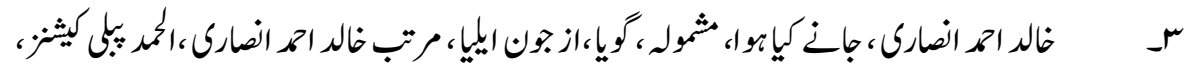
لانورره+r.

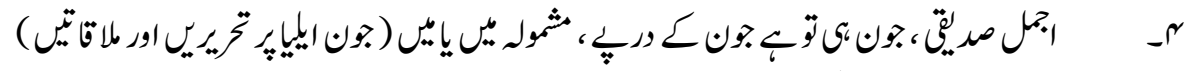

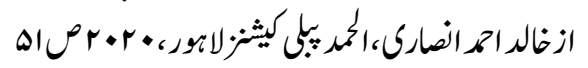

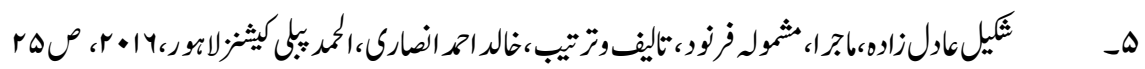

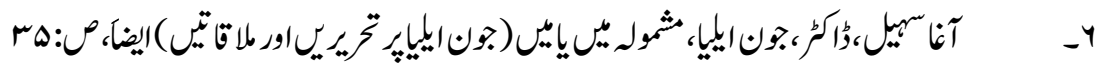

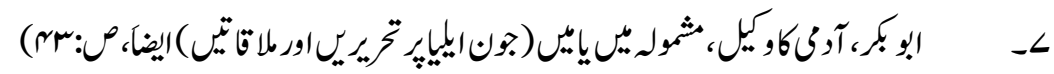

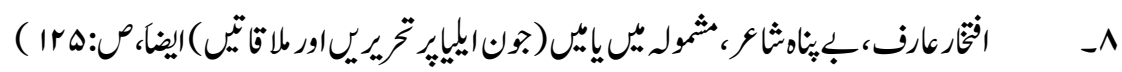

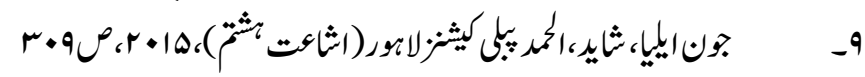

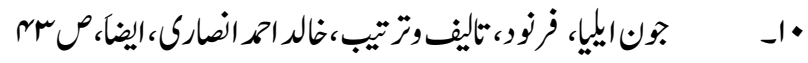

$$
\begin{aligned}
& \text { 11 }
\end{aligned}
$$

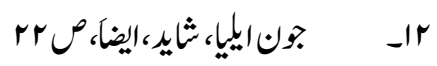

$$
\begin{aligned}
& \text { با- } \\
& \text { rr }
\end{aligned}
$$

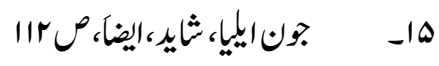

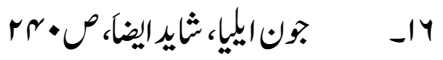

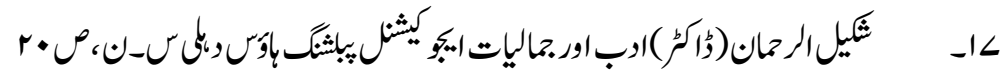

$$
\begin{aligned}
& \text { 11 }
\end{aligned}
$$

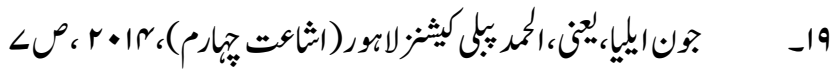

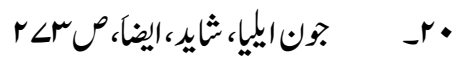

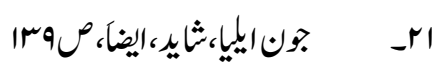

$$
\begin{aligned}
& \text { rr }
\end{aligned}
$$

